\title{
Repurposing FDA approved drugs against the human fungal pathogen, Candida albicans
}

\author{
Kevin Kim, Leeor Zilbermintz and Mikhail Martchenko*
}

\begin{abstract}
Background: The high cost and prolonged timeline of new drug discovery and development are major roadblocks to creating therapies for infectious diseases. Candida albicans is an opportunistic fungal pathogen that is the most common cause of fatal fungal infections in humans and costs \$2-4 billion dollars to treat in the US alone.

Methods: To accelerate drug discovery, we screened a library of 1581 existing FDA approved drugs, as well as drugs approved abroad, for inhibitors of C. albicans. The screen was done on YPD yeast growth media as well as on the serum plate assay developed in this study.

Results: We discovered that fifteen drugs, all which were originally approved for treating various infectious and noninfectious diseases, were able to kill Candida albicans. Additionally, one of those drugs, Octodrine, displays widespectrum anti-microbial activity. Compared to other selected anti-Candida drugs, Octodrine was shown to be one of the most effective drugs in killing serum-grown Candida albicans without significantly affecting the survival of host macrophages and skin cells.
\end{abstract}

Conclusions: This approach is useful for the discovery of economically viable new therapies against infectious diseases.

Keywords: Antifungal, Drug-discovery, Off-label drug use, Small molecules

\section{Background}

While almost all of us possess Candida albicans in our oral cavity, gastrointestinal tracts, genitourinary tracts, and on skin as a relatively harmless commensal organism, C. albicans is a major systemic fungal pathogen in humans [1]. Candida evades and escapes from the host's innate immunity, causing irritating and recurrent infections that can range from thrush in immunocompetent colonized hosts, to lifethreatening systemic infections in immunocompromised individuals such as patients with HIV, or those receiving immunesuppressing cancer chemotherapy and corticosteroids. Surprisingly, only 10 to $20 \%$ of individuals who develop bloodstream Candida infections are seriously immunocompromised. A large majority of patients develop Candida infections because they have become more susceptible while hospitalized due to the use of broad-spectrum antibiotics, surgery, and intravenous catheters. As a result, infections from $C$. albicans ranks as the fourth most

\footnotetext{
* Correspondence: mikhail_martchenko@kgi.edu

Keck Graduate Institute, Claremont, CA 91711, USA
}

common hospital-acquired infection in the United States. The cost of treating bloodstream Candida infections is \$24 billion per year in the US alone [2]. In the US, annual incidence of systemic candidiasis is approximately 70,000 cases per year, which results in the death rate of about 30 to $40 \%$, even after treatment with antifungal therapy [3].

The situation is especially grave in cancer patients. The incidence of Candida infection in all cancer patients is very high, ranging from 40 to $88 \%[4,5]$. The mortality rate among the Candida infected cancer patients reaches an alarmingly high $75 \%$ amongst the Filipino and Pacific Islanders [5]. Early antifungal treatment, although poorly tolerated by the host, is mandatory to improve the survival of cancer patients. Unfortunately, $30 \%$ of Candida isolates are resistant to all antifungal treatments [6].

Host serum plays a prominent role in the pathogenicity of C. albicans. On the one hand, serum promotes morphological switching of Candida from yeast to hyphal forms, which is necessary for its evasion of phagocytosis and organ colonization [7]. On the other hand, serum is known to 
inhibit the activity of known antifungal drugs [8]. Taken together, these laboratory observations explain in part the clinical mortality observed during Candida blood infections, even when patients are treated with antifungals [5].

Several clinical and laboratory data suggests that currently available antifungal therapies are mostly ineffective in treating Candida infections [9]. Despite extensive research dedicated to the development of new therapeutic strategies, there are only a limited number of available drugs to fight against invasive fungal infections. Indeed, only four molecular classes targeting three distinct fungal metabolic pathways are currently used in clinical practice to treat systemic fungal infections. These include: fluoropyrimidine analogs, polyenes, azoles, and echinocandins $[9,10]$. However, the efficacy of some of these drugs is severely limited because of their unacceptable toxicity, poor activity in blood, or the emergence of resistance; thereby underscoring an urgent necessity for new antifungal agents. Several other classes, such as morpholines and allylamines are only used as topical agents due to either their poor efficacy, or severe adverse effects when administered systemically $[9,10]$.

Unfortunately, the development of an entirely new drug is a long and expensive process. New drugs have to undergo an arduous approval process by the FDA in order to establish safety of the drug for human consumption [11]. We propose that the repurposing of existing FDAapproved drugs as antifungal agents may decrease the time and effort of bringing drugs with novel antifungal activity from the bench to the bedside. Recently, another group investigated the ability of FDA-approved drugs to inhibit C. albicans biofilm formation by screening the Prestwick Library, a commercially available chemical library of 1200 drugs [12]. However, C. albicans biofilm formation is just one of many pathogenesis strategies, such as yeast-to-hyphal phenotypic switching, white-opaque phenotypic switching, ability to adhere to mammalian tissues, and secretion of aspartyl proteinases [1, 7]. The goal of this study is to identify drugs capable of killing blood-borne Candida albicans, and we use serum as an in vitro surrogate of host blood. To this end, we have tested the anti-Candida activity of drugs from the Johns Hopkins Clinical Compound Library (JHCCL) [13] on Candida grown on serum-containing media. This library consists of drug-compounds that are FDA-approved with a diverse range of functions, mechanisms of action and wellcharacterized pharmacological and toxicological properties.

\section{Methods}

\section{Candida albicans and bacterial strains}

Strain SN250 is the wild type reference strain of C. albicans. It serves as the reference strain for our genetic knockout library screen. It is derived from the wild type strain SC5314, a human clinical isolate recovered from a patient with generalized candidiasis [14]. SN250 was used for drug screening experiments. The bacterial strains consisted of Bacillus cereus strain 10987 and Escherichia coli strain C600. The genetic screen for mutant sensitivity to Octodrine was tested with three $C$. albicans libraries that were previously created in [15-17].

\section{Media and growth conditions}

C. albicans strains were cultured in liquid YPD medium at $30{ }^{\circ} \mathrm{C}$ overnight. E. coli and B. cereus were cultured in liquid $\mathrm{LB}$ medium at $37{ }^{\circ} \mathrm{C}$ and $30{ }^{\circ} \mathrm{C}$, respectively, shaking overnight. A novel method to incorporate fetal bovine serum to agar was devised. Fetal bovine serum was preheated in a water bath set at $65{ }^{\circ} \mathrm{C}$. We found that isothermal conditions of the two mixtures eliminated the formation of foam upon coalescence. The agar solution for the serum mixture consisted of $16 \mathrm{~g}$ agar, which was then brought up to $300 \mathrm{ml}$ with nanopure water. The agar solution was then autoclaved at $120{ }^{\circ} \mathrm{C}$ for $45 \mathrm{~min}$. The agar and serum mixtures were then amalgamated while in their isothermal states.

\section{Chemicals}

An FDA-approved drug library comprising of 1500 drugs was purchased from Johns Hopkins, titled, Johns Hopkins Clinical Compound Library (JHCCL) version 1.0. The drugs arrived as $10 \mathrm{mM}$ stock solutions in sealed microtiter plates and were made using DMSO or water as solvents. Drugs were arrayed in 96-well plates and screened at a stock concentration of $10 \mathrm{mM}$. Drugs were from Fisher and Sigma and were of the highest purity available. The library was stored at $-20{ }^{\circ} \mathrm{C}$ until use. Prior to use, the library of drugs was thawed at room temperature. Drugs of interest were isolated and reproduced from prepared $10 \mathrm{mM}$ solutions. Antimycin A, Captan, Chlorquinaldol, Clotrimazole, Disulfiram, Fluvastatin, Mycophenolic Acid, Methylbenzethonium Chloride, Miconazole, Nitroxoline, Octodrine, Pyrithione Zinc, Fluconazole, and Octanoic Acid were purchased from Sigma-Aldrich (St. Louis, MO, USA). Nifuroxime was purchased from MP Biochemicals (Solon, OH, USA). All drugs were prepared to $10 \mathrm{mM}$ using DMSO as the solvent. DMSO was purchased from $\mathrm{Amresco}^{\circ}$ (Solon, OH, USA). Fetal bovine serum (Triple Membrane $0.1 \mu \mathrm{m}$ filtered) was purchased from GeneMate BioExpress (Kaysville, UT, USA).

\section{Screening assay}

The sensitivity of $C$. albicans to drugs was assessed by a chemical screen. The absorbance at optical density at $600 \mathrm{~nm}\left(\mathrm{OD}_{600}\right)$ of yeast and bacterial overnight cultures were determined for each of our experiments. The absorbance values were then converted to cells $/ \mathrm{ml}$ using McFarland's scale. Twenty five million Candida cells were added to all $10 \mathrm{~cm}$ petri dishes; 600 million bacterial cells were added to all $10 \mathrm{~cm}$ bacterial petri dishes. 
Five microlitre of each drug was placed directly on the agar surface using a multichannel pipette and slight contact of the tip to the agar made to leave an impression to facilitate later analysis. Drugs that were replicated were done on petri dishes, following the same protocol in at least five independent experiments. For the replication studies, only a single drug was placed per plate. The plates were incubated at either 25 or $37^{\circ} \mathrm{C}$ for $24 \mathrm{~h}$. The drugs-of-interest were selected on their ability to produce a distinct zone of inhibition of fungal growth greater than the zone made by DMSO alone and at the same time that is comparable to, if not greater than the positive control, Fluconazole. The zones of inhibition were quantified by measuring their diameters in $\mathrm{mm}$, as recommended by the Clinical Laboratory Standards Institute (CLSI) procedures outlined in the manual M44A2 $[18,19]$. In addition, we utilized the software ImageJ [20] to digitally quantify the magnitude of every zone of inhibition.

E. coli and B. cereus were cultured overnight in liquid $\mathrm{LB}$ media at 37 and $30{ }^{\circ} \mathrm{C}$ respectively. The sensitivity of E. coli and B. cereus to Octodrine was assessed by spreading $6 \times 10^{8}$ cells of their respective overnight cultures onto petri dishes containing solid LB media. $5 \mu \mathrm{l}$ of neat Octodrine was placed directly on the agar surfaces. The plates with $E$. coli were incubated at $37{ }^{\circ} \mathrm{C}$, while plates with B. cereus were incubated at $30^{\circ} \mathrm{C}$ for $24 \mathrm{~h}$.

\section{Determination of minimal effective drug concentrations by drug diffusion susceptibility testing}

Plates inoculated with $C$. albicans were prepared using the protocol described above. To elucidate the ability of the varying concentrations of drugs to form zones of inhibition, two-fold serial drug dilution experiments were performed. To perform the first two-fold dilution, one part of the $10 \mathrm{mM}$ stock solution was mixed with one part DMSO. Each subsequent dilution was done with aliquots from the prior dilution mixed with equal parts of DMSO. $5 \mu \mathrm{l}$ of each drug dilution was spotted onto a lawn grown on YPD plate, as well as $5 \mu \mathrm{l}$ of DMSO as a negative control. Dilutions beyond $0.07813 \mathrm{mM}$ that were still forming a significant zone of inhibition were further diluted on a separate plate. Drug-treated plates were then incubated at either 25 or $37{ }^{\circ} \mathrm{C}$ for $24 \mathrm{~h}$. Twofold serial dilutions of Octodrine were done on YPD and Serum plates with undiluted Octodrine as the most concentrated solution.

\section{Genotypic mutant screening against Octodrine}

Each C. albicans knockout strain from one of the three $C$. albicans libraries [15-17] was cultured in individual wells of 96 well plate in $100 \mu \mathrm{l}$ of YPD media overnight at $30^{\circ} \mathrm{C}$. $5 \mu \mathrm{l}$ of each Candida knockout overnight culture was spotted onto a YPD solid plate using a multichannel pipette.
The cells were then left to absorb into the YPD plates for $1 \mathrm{~h}$ at $25{ }^{\circ} \mathrm{C}$. Using a multichannel pipette, $5 \mu \mathrm{l}$ of Octodrine $10 \mathrm{mM}$ was spotted directly on top of the C. albicans cells. The plates were then placed in an incubator set at $30{ }^{\circ} \mathrm{C}$ and left overnight. Analysis of plates consisted of isolating any strains that exhibited resistance to $5 \mu \mathrm{l}$ of $10 \mathrm{mM}$ Octodrine. Resistance was noted by the ability of the Candida cells and the subsequent drug-treated spot to lack a zone of inhibition.

\section{Mammalian cell culture, drug treatment, and survival assay}

RAW264.7 mouse macrophage cells (ATCC number TIB71) and human melanoma C32 cells (ATCC number CRL-1585) were maintained in DMEM (Sigma-Aldrich) supplemented with $10 \%$ FBS (Bioexpress) and $100 \mu \mathrm{g} / \mathrm{mL}$ penicillin and $100 \mu \mathrm{g} / \mathrm{mL}$ streptomycin. Mammalian cells (10,000 per well) were seeded in 96-well plates $(100 \mu \mathrm{l} /$ well) $24 \mathrm{~h}$ before the assay. During the assay, $1 \mu \mathrm{l}$ of $10 \mathrm{mM}$ drug was added to $100 \mu \mathrm{l}$ of cell-containing media. Two-fold serial dilutions of the media were performed. RAW264.7 and C32 cells were treated with drugs for 24 and $48 \mathrm{~h}$ respectively, and determination of cell viability by 3-(4,5-dimethylthiazol-2-yl)-2,5-diphenyltetrazolium bromide (MTT) assay was performed as described in [21]. Each data point shown in the figure for MTT assays represents the average of results from at least two wells in each of at least two separate experiments. Cell viability is shown as the percentage of survivors obtained relative to untreated cells grown in media only (100 \%).

\section{Image capture and image processing}

All images were taken with an 8MP iSight camera with an aperture size of F2.4 and touch-to-focus capabilities. Images were standardized with a universal template to allow for direct comparison between images. Images are stock and unaltered by any graphics editing software.

\section{Results \\ Moderate ability of Fluconazole to kill serum-grown Candida albicans at $37^{\circ} \mathrm{C}$}

It has been reported that host serum markedly inhibits growth of the human fungal pathogen, Candida albicans [22-24]. We have confirmed these observations by showing that Candida wild type strain SN250 [15] is unable to grow in liquid $100 \%$ Fetal Bovine Serum at either 25 or $37{ }^{\circ} \mathrm{C}$ (data not shown). However, during the course of our experiments, we have observed that Candida is able to grow and establish a lawn on solid serum plates containing $62.5 \% \mathrm{v} / \mathrm{v}$ FBS and $37.5 \% \mathrm{v} / \mathrm{v}$ agar solution, at both temperatures (Fig. 1a).

We investigated whether Fluconazole, the widely used anti-Candida drug, was able to kill C. albicans on solid serum plates. While Fluconazole was shown to be an 


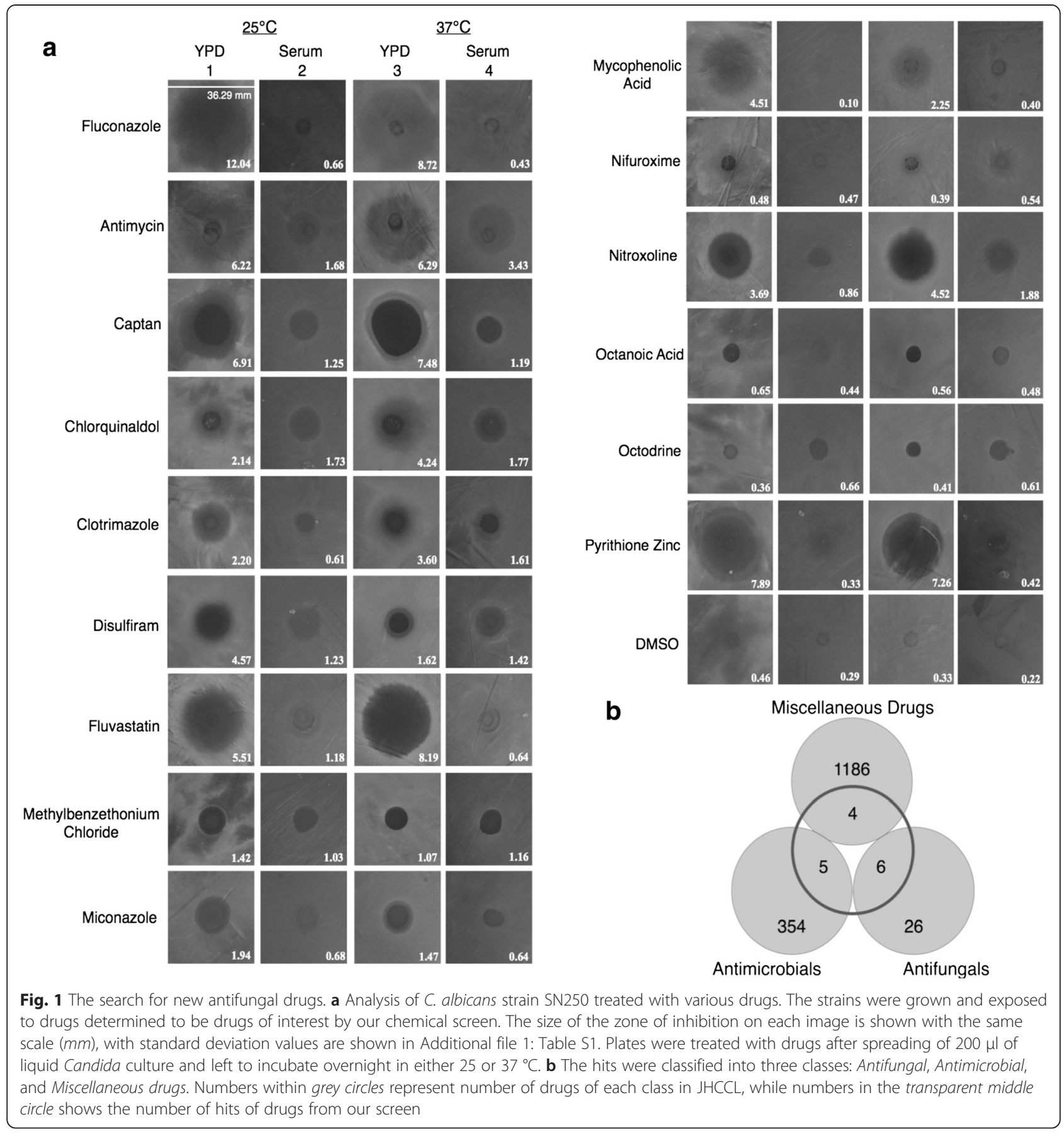

effective inhibitor of Candida growth on standard solid YPD plates, (Fig. 1a), we observed that Fluconazole moderately inhibits the growth of Candida on serum plates (Fig. 1a and Additional file 1: Table S1). It should be noted, however that Fluconazole formed prominent zone of inhibition on the solid YPD plates. In addition, we observed that Fluconazole exhibited diminished effectiveness at forming zone of inhibition at $37{ }^{\circ} \mathrm{C}$ compared to $25{ }^{\circ} \mathrm{C}$ (Fig. 1a and Additional file 1: Table S1). We decided to assess the drug-pathogen interactions at
$25{ }^{\circ} \mathrm{C}$ in additional to body temperature because there is a serious problem of Candida growth in catheters where it may be exposed to serum at room temperatures [25].

\section{Screening of inhibitors of Candida albicans lawn formation}

In light of the moderate effectiveness of Fluconzole to kill C. albicans in serum at the physiologically relevant temperature $\left(37{ }^{\circ} \mathrm{C}\right)$, and in search for alternative antifungal drugs, we decided to screen the library of chemicals 
[13] approved by the FDA for human use for their ability to kill Candida albicans. JHCCL consists of 1581 FDAapproved drugs, as well as drugs approved abroad, consisting of small molecules $(10 \mathrm{mM})$ that are used as treatments for a variety of diseases, including, but not limited to: infectious, neurodegenerative, psychiatric, cardiovascular diseases and cancer.

We identified inhibitors of Candida growth formation by performing a primary screen on the 1581 drugs belonging to the JHCCL. We plated Candida on solid YPD and serum plates, and placed $5 \mu \mathrm{l}$ of each $10 \mathrm{mM}$ drug on top of the fungal lawn. We tested the effect of exposure to each of the drugs from the library on their ability to inhibit Candida growth, as well as their ability to form a zone of inhibition within the fungal lawn. Based on this screen, we identified 15 drugs that inhibit Candida growth on solely YPD or on both YPD and serum plates in at least five independent experiments at two temperatures, $25{ }^{\circ} \mathrm{C}$ and $37{ }^{\circ} \mathrm{C}$ (Fig. 1a). We classified the 15 hits into three different classes to facilitate interpretation of our results. They were: 6 hits from 32 known antifungals, 5 hits from 359 antimicrobials/antiseptics, and 4 hits from 1190 other multifunctional drugs (Fig. 1b). While these drugs were chosen in these screens for their ability to inhibit C. albicans lawn formation, the actual levels of inhibition varied from weak to strong inhibition (Fig. 1a and Additional file 1: Table S1).

All 6 selected antifungal drugs, Antimycin A, Captan, Clotrimazole, Fluconazole, Miconazole, and Pyrithione Zinc showed strong inhibition of Candida growth on YPD plates at $25{ }^{\circ} \mathrm{C}$ and $37{ }^{\circ} \mathrm{C}$ (Fig. 1a and Additional file 1: Table S1). However, with the exception of the pesticide Captan, all of the antifungals exhibited weak inhibition of Candida growth on serum plates (Fig. 1a and Additional file 1: Table S1).

Out of the five antimicrobial/antiseptic drugs selected by our screen, Chlorquinaldol and Methyl-benzethonium chloride displayed the strongest inhibition of $C$. albicans growth on serum plates. Nifuroxime, Nitroxoline, and Octanoic acid showed weaker inhibition of Candida growth on serum plates (Fig. 1a and Additional file 1: Table S1).

Interestingly, from a drug-repurposing point of view, 4. drugs from 1190 of the other multifunctional drugs, showed anti-Candida activity on YPD plates (Fig. 1a and Additional file 1: Table S1). Of those, Fluvastatin and Mycophenolic acid showed very strong inhibition of YPD grown Candida, but failed to inhibit its growth on serum plates (Fig. 1a and Additional file 1: Table S1). The other 2 drugs, Disulfiram and Octodrine showed a consistent moderate-to-weak anti-Candida activity on YPD and serum plates (Fig. 1a and Additional file 1: Table S1).

\section{Diffusion susceptibility testing of the hits obtained from the screen}

The 15 hits from the primary screen consisting of antifungals, antimicrobials, and miscellaneous drugs were tested in diffusion susceptibility assays in order to determine their potency against $C$. albicans lawns. These confirmatory screenings were performed over a range of drug concentrations, where $5 \mu \mathrm{l}$ of drugs within the range of $10 \mathrm{mM}$ to $0.3 \mu \mathrm{M}$ were applied on YPD-grown Candida cells and plates were incubated for $24 \mathrm{~h}$. YPD plates were chosen as the testing media since some of the drug hits were ineffective in inhibiting fungal growth on serum plates. The efficacy of each drug was evaluated by estimating the inhibitory concentration at which the drug formed a zone of inhibition on a fungal lawn of YPD plates.

We found that with the exception of Fluconazole and Captan, all antifungals were able to inhibit Candida growth in the $\mu \mathrm{M}$ drug range (Fig. 2 and Additional file 1: Table S2). All five antimicrobial and antiseptic drugs were only able to inhibit fungal growth in the $\mathrm{mM}$ drug concentrations (Fig. 2 and Additional file 1: Table S2). Surprisingly, among the drugs approved for non-infectious disease treatments, Fluvastatin was able to inhibit $C$. albicans growth in the $\mu \mathrm{M}$ drug concentration, while the rest of the drugs were only inhibitory in the $\mathrm{mM}$ drug concentrations.

\section{Broad-spectrum antimicrobial properties of Octodrine}

Although nine antimicrobial and non-antimicrobial drugs we discovered have not been approved by FDA to treat fungal infections, eight of them were found previously to kill Candida albicans [26-39]. Octodrine, the drug previously used as a decongestant $[40,41]$, showed an ability to kill serum-grown $C$. albicans when applied at $10 \mathrm{mM} 5 \mu \mathrm{l}$ drop (Fig. 1). Furthermore, Octodrine is the only drug that has not been tested to kill fungi previously. We wanted to investigate whether the application of an even higher concentration of Octodrine would augment its antifungal properties. To test this, we applied $5 \mu \mathrm{l}$ of neat, undiluted Octodrine, which is produced in a liquid form, as well as its two-fold serial dilutions on the serum and YPD grown Candida lawn. We discovered that the undiluted amount of Octodrine was effective in eliminating the fungal growth (Figs. 3 and 4 and Additional file 1: Tables S3 and S4). We also observed that Octodrine is more effective in inhibiting serum grown Candida compared to YPD grown Candida, as the inhibitory concentrations of Octodrine were more pronounced on serum than on YPD plates (Fig. 3, Additional file 1: Table S3).

In order to identify Candida proteins and signaling pathways that mediate the lethality of Octodrine, we screened three $C$. albicans knockout libraries, collectively consisting of 908 mutant strains lacking one of the previously demonstrated virulence genes, for any alterations in sensitivity to $10 \mathrm{mM}$ Octodrine. These libraries 


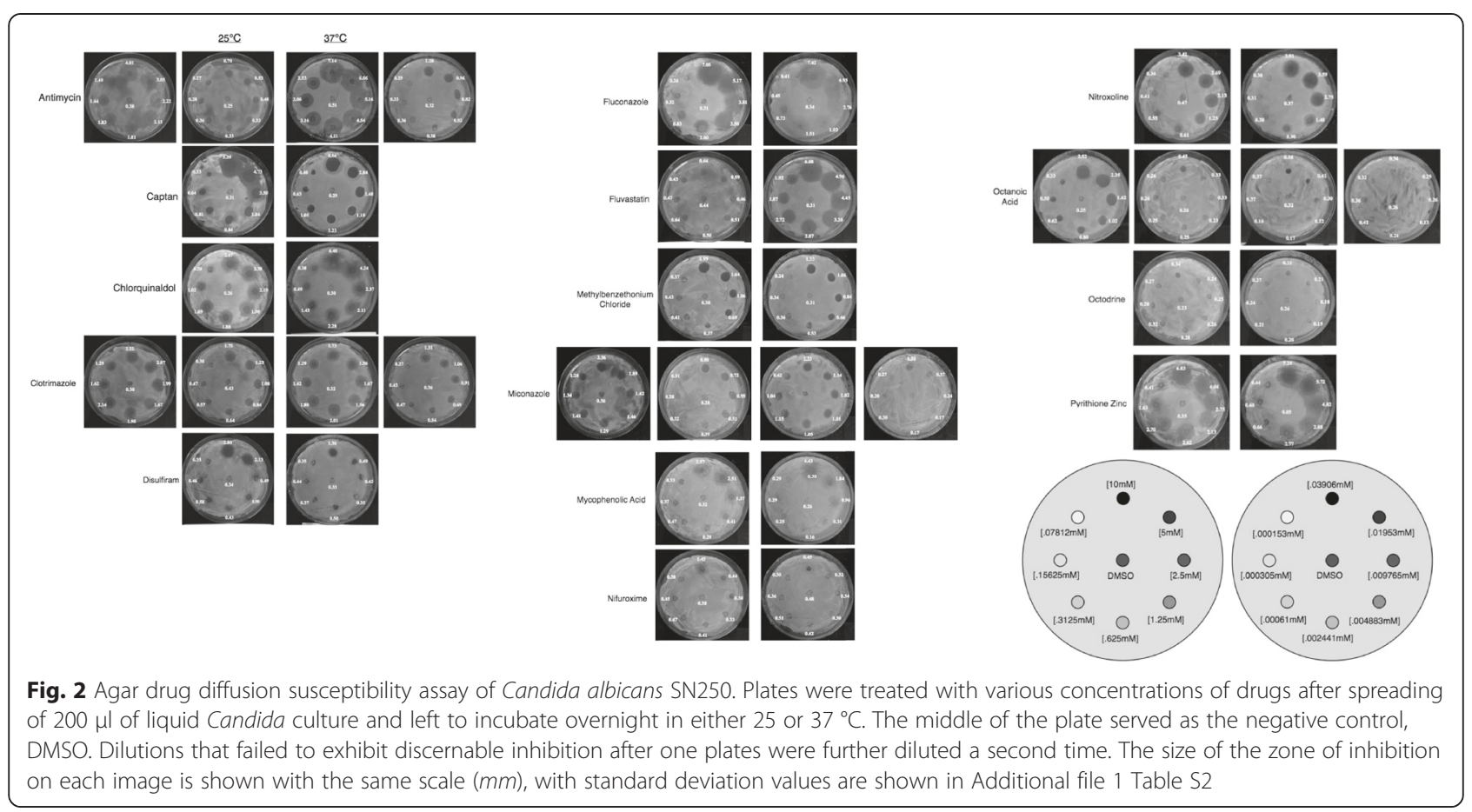

consisted of 647 mutant strains lacking one of the essential virulence genes [15], 96 cell wall protein mutants [42], and 165 transcription factors mutants [43]. We found that all Candida mutants were as sensitive to $5 \mu \mathrm{l}$ of $10 \mathrm{mM}$ Octodrine as the wild type strain (Additional file 1 Figure S1).

We hypothesized that Octodrine may kill microorganisms by targeting their non-protein cellular components. To investigate this we tested the sensitivities of Escherichia coli strain C600 and Bacillus cereus strain 10987, gramnegative and gram-positive bacteria, respectively, and frequent disease-causing bacteria, to Octodrine. These bacterial strains were chosen because they are wild type strains with known genotypes and genomes [44, 45]. We observed that $5 \mu \mathrm{l}$ of neat Octodrine formed a prominent zone of inhibition in both $E$. coli and B. cereus lawns (Fig. 4 and Additional file 1: Table S4), which suggests that Octodrine possesses wide spectrum antimicrobial properties.

Since Octodrine was one of the most prominent drugs that killed C. albicans in serum, we tested the sensitivity of mouse macrophage cell line RAW264.7 to Octodrine, and compared it to the rest of selected drugs. Since Octodrine stock was dissolved in DMSO, we had to test the sensitivity of the cell line to this solvent alone. Cell viability was determined by MTT assay (Methods) and was calculated as the percentage of surviving cells in various chemical concentrations relative to cells treated with media alone. We observed that the sensitivity of mouse macrophages to Octodrine was the close to the sensitivity to the DMSO alone (Table 1). This strongly suggests that Octodrine concentrations that kill Candida albicans in serum (Fig. 1a) do not affect the survival of host phagocytes. The sensitivity of RAW264.7 cells to DMSO has previously been reported [46], and is consistent with the cellular sensitivity seen here. We tested the sensitivity of RAW264.7 macrophage like cells because macrophages are first line of defense against Candida, and knowing the sensitivity of those cells to antifungal is an important question. We confirmed these observations by testing sensitivity of human skin melanoma cell line, C32 (Table 1). With the exception of Octodrine, Floconazole, Nifuroxime, and Fluvastatin, all other selected drugs adversely affected the survival of host cells, which suggests that they may have undesirable side effects when used in blood. We chose this cell line because of the relevance of skin to Candida infections.

\section{Discussion}

This study was designed to test FDA and foreign-approved small molecules drugs for their antifungal properties, with the objective of reducing the cost and time necessary to develop much needed anti-Candida albicans therapies. This library consists of an FDA-approved, off-patent collection of 1581 small molecules $(10 \mathrm{mM})$ that are used as drugs for a variety of diseases, including infectious, neurodegenerative, psychiatric, cardiovascular diseases and cancer. Such an approach would rapidly expedite the drug discovery and development process since the general pharmacology, toxicology, and pharmacokinetic properties of all these drugs are already well established. This would facilitate the further analysis of the novel functionalities of the established molecules because the structure, chemical 


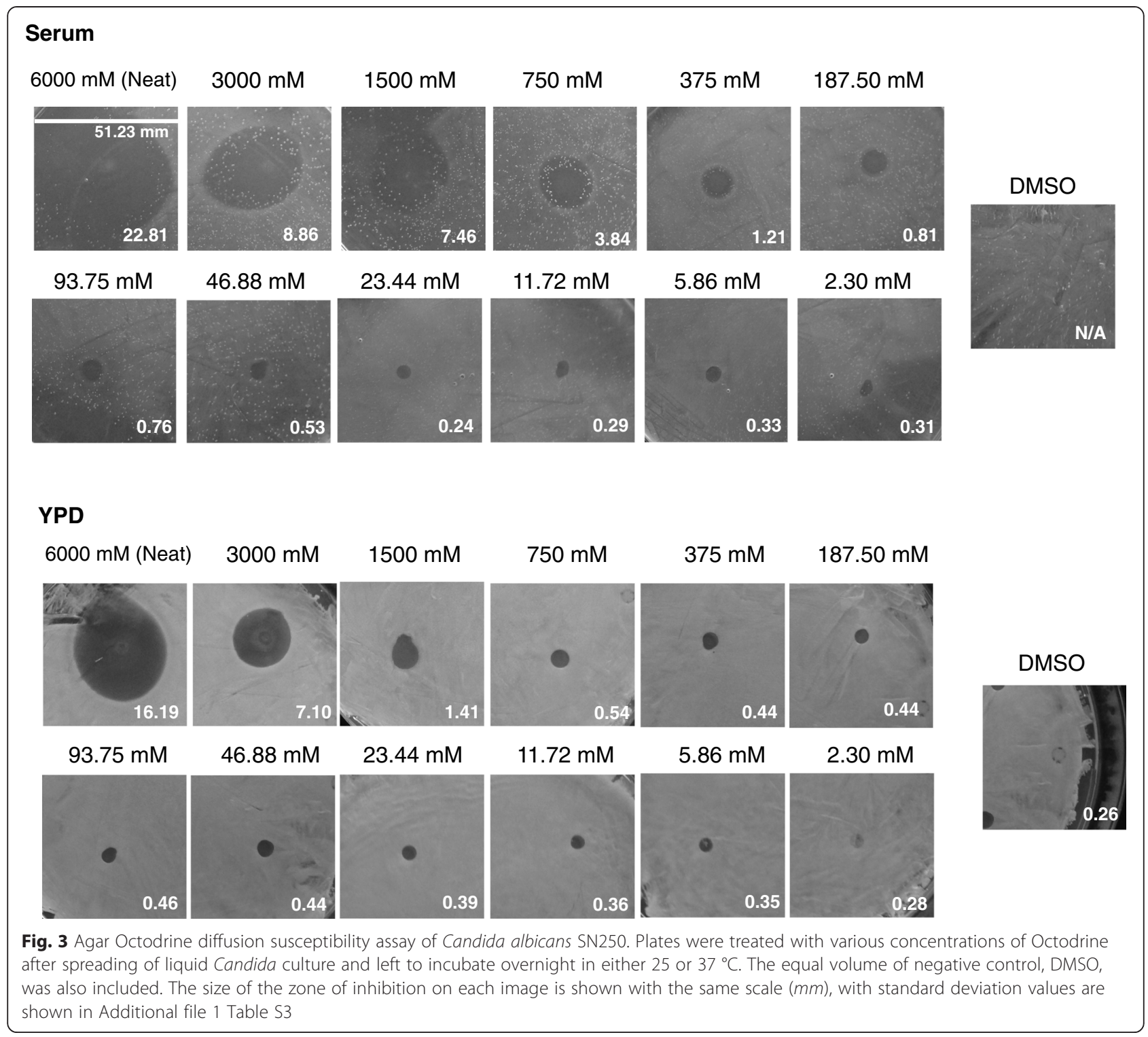

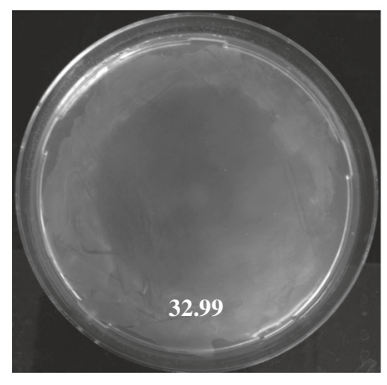

Candida albicans

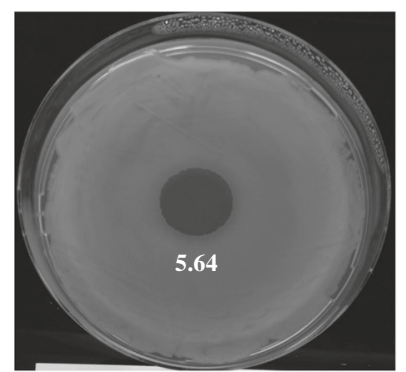

Bacillus cereus

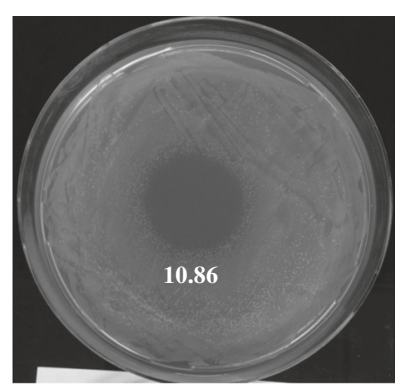

Escherichia coli

Fig. 4 The sensitivities of Candida albicans, Escherichia coli, and Bacillus cereus to neat Octodrine. Plates were treated with $5 \mu$ l of undiluted Octodrine after spreading of $200 \mu \mathrm{l}$ of liquid Candida $\left(25 \times 10^{6}\right.$ cells) or bacterial cultures $\left(600 \times 10^{6}\right.$ cells) on $10 \mathrm{~cm}$ petri dish and left to incubate overnight in either $37^{\circ} \mathrm{C}$ for $\mathrm{C}$. albicans and $\mathrm{E}$. coli or in $30^{\circ} \mathrm{C}$ for B. cereus. The size of the zone of inhibition on each image is shown with the same scale $(\mathrm{mm})$, with standard deviation values are shown in Additional file 1 Table $\$ 4$ 
Table 1 Minimal cytotoxic concentration (MCC) calculations for the cell lines RAW264.7 and C32 treated with selected drugs

\begin{tabular}{lcc}
\hline Drug & MCC $(\mu \mathrm{M})$ RAW264.7 & MCC $(\mu \mathrm{M})$ C32 \\
\hline Fluconazole & 100.00 & 100.00 \\
Antimycin & 3.13 & 0.098 \\
Captan & 12.50 & 12.50 \\
Chlorquinaldol & 0.20 & 6.25 \\
Clotrimazole & 6.25 & 12.50 \\
Disulfiram & 12.50 & 12.50 \\
Fluvastatin & 50.00 & 6.25 \\
Methylbenzethonium Chloride & 6.25 & 1.56 \\
Miconazole & 6.25 & 1.56 \\
Mycophenolic Acid & 0.78 & 1.56 \\
Nifuroxime & 25.00 & 25.00 \\
Nitroxoline & 6.25 & 6.25 \\
Octanoic Acid & 0.78 & 6.25 \\
Octodrine & 25.00 & 25.00 \\
Pyrithione Zinc & 0.78 & 1.56 \\
DMSO & 50.00 & 50.00 \\
\hline
\end{tabular}

The solvent DMSO is used as a negative control. Mammalian cells were treated with drugs at concentrations shown. The drugs were serially-diluted, and the MCC is defined as the first concentration of the drug, which is able to lower cell viability below $100 \%$. Cell viability was determined by MTT assay (Methods) and is shown as the percentage of survivors relative to cells treated with media alone

properties, and biological functions of almost all members of this library are known.

We have developed a serum-based assay to address the limitations of currently used YPD media, whose components do not represent in vivo components that support the growth of Candida. The moderate-to-mild effectiveness of Fluconazole and other FDA approved antifungal drugs on our serum assay is comparable to the effectiveness of Octodrine in killing serum-grown C. albicans.

In our study, fifteen out of 1581 drugs displayed antiCandida properties. Overall, all drugs discovered in our study could be separated into three structural categories: five-membered heterocyclic drugs, such as azoles and oxoles, six-membered heterocyclic compounds (pyridines), and other structures (Fig. 5). The fact that we selected six drugs that were previously approved by FDA to treat fungal infections biologically validates our approach. The six antifungal drugs obtained as hits from the screen comprised three different chemical classes: azoles (Fluconazole, Captan, Clotrimazole, and Miconazole), pyridine (Pyrithione Zinc), and other structures (Antimycin A). Additionally, we found five antimicrobial/antiseptic drugs to be effective at inhibiting $C$. albicans lawn formation in the screen. These drugs include general antiseptics and antibacterial antibiotics, and comprise three different chemical classes: oxoles (Nifuroxime), pyridines (Nitroxoline and Chlorquinaldole), and other structures (Octanoic acid and Benzethonium Chloride) (Fig. 5). The fact that these five other drugs that were approved by FDA to treat other non-fungal infectious diseases were also observed to kill Candida albicans shows that these drugs could be repurposed to be broad-spectrum anti-microbial drugs.

Lastly, from the point of view of drug repurposing, the most interesting class of drugs would be the one with demonstrated activity against a variety of diseases, but with no known or characterized antifungal activity to date. From the screen, we found four drugs belonging to this class to be effective in preventing Candida growth. These drugs have been designed for several indications, including immune-suppression (Mycophenolic acid), deterrent of alcohol consumption (Disulfiram), antihyperlipidemic (Fluvastatin), and decongestant (Octodrine). These drugs comprise three different chemical classes: azole (Fluvastatin), oxole (Mycophenolic acid), and other structures (Disulfiram and Octodrine) (Fig. 5). These four drugs that were approved to treat non-infectious diseases showed antifungal properties and thus, could be repurposed as new antifungal drugs.

Recently, another group investigated the ability of FDAapproved drugs to inhibit C. albicans biofilm formation [12] by screening the Prestwick Library, a commercially available chemical library of 1200 drugs. Interestingly, the authors of that paper discovered several antifungal drugs in common to our study: Miconazole, Clotrimazole, and Methylbenzonium chloride. The difference between the two studies is that Siles et al. [12] screened for drugs capable of inhibiting Candida biofilm formation, while we looked for FDA approved drugs capable of inhibiting the growth of non-biofilm C. albicans growth. In addition, with the exception of Octodrine, every one out of fifteen discovered drugs in our study had been previously tested for the ability to kill Candida albicans [26-39].

In this study, Octodrine, which was previously used as a decongestant and registered under the name of Vaporpac (Medley \& James Laboratories) [40, 41], was a drug that had not been previously established as an anti-fungal. We observed that although its anti-Candida activity was mild on YPD, it displayed one of the best Candida growth inhibition on serum compared to other drugs. It also has a potential to be one of the safest of the discovered drugs because it did not affect the sensitivity of mammalian cells significantly. The fact that no C. albicans mutants showed a decrease in sensitivity to Octodrine argues against the potential emergence of Octodrine-resistant Candida strains, and favors the usage of this drug as a new antifungal treatment against Candida. In addition, we showed that Octodrine is capable of killing Gram-positive as well as Gram-negative bacteria, making it a desirable broadspectrum antimicrobial countermeasure, that probably kills microbes by targeting their non-protein components. Octodrine was previously shown to agonize Estrogen 


\section{5-Member Heterocyclic compounds: Azoles and Oxoles}
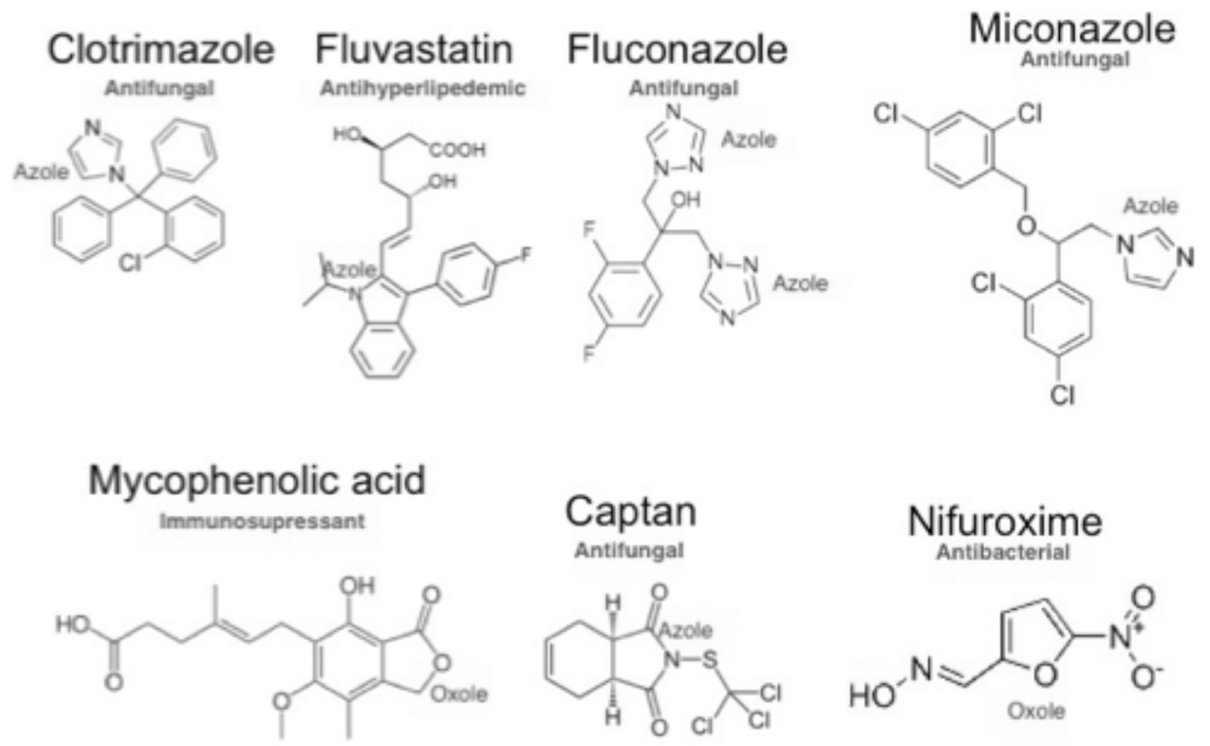

\section{6-Member Heterocyclic compounds: Pyridines}

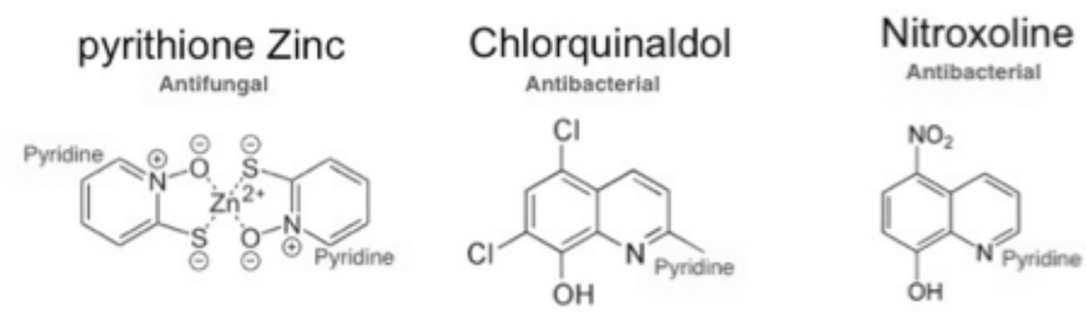

\section{Miscellaneous structures}
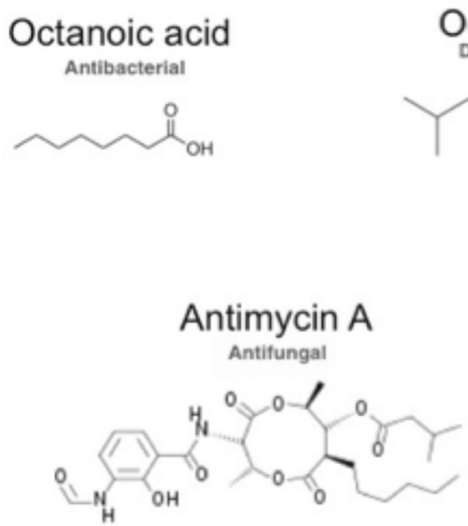
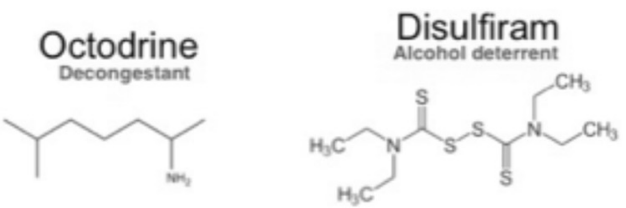

Fig. 5 Chemical structures of 15 drugs shown to have anti-Candida albicans activity in our screen. All drugs were categorized into 3 classes: 5-membered heterocyclic (Azoles and Oxoles) and 6-membered heterocyclic (Pyridines) compounds, as well as drugs of other structures. The FDA approved applications are shown in green. Substructures are indicated in red 
Receptor Alpha with the potency of $21 \mu \mathrm{M}$ [47]. Thus, any in vivo antimicrobial activity of Octodrine in humans would have to be in the $\mathrm{nM}$ range to avoid this side effect. As the pharmacokinetics of Octodrine had been previously established in numerous animal models [48], this approach is useful for the discovery of economically viable new therapies against infectious diseases.

\section{Conclusions}

In summary, we have screened the Johns Hopkins Clinical Compound Library, a commercially available chemical library of FDA approved 1581 drugs, for the identification of bioactive drugs against $C$. albicans growth. Our results provide the comprehensive survey of the inhibition of Candida growth by existing drugs, one of which hadn't been previously reported to have antifungal properties. From a drug repurposing point of view, the identification of drugs with no known antifungal activity and which demonstrated excellent activity against $C$. albicans growth in serum opens up a valuable new avenue for the rapid development of antifungal agents, which are urgently needed.

\section{Additional file}

Additional file 1: Quantification of the zone of inhibition posttreatment of various drugs on C. albicans strain SN250. Quantification of the zone of inhibition post-treatment of various serially diluted drugs on C. albicans strain SN250. Serial dilution experiments of Octodrine on serum and YPD plates. Quantification of the zone of inhibition of Octodrine in neat form against Candida albicans, Escherichia coli and Bacillus cereus. Elucidation of mechanism of Candida albicans: Elucidation of Candida albicans sensitivity to Octodrine.

\section{Competing interests}

The authors declare that they have no competing interests.

\section{Author's contributions}

K.K. and M.M. designed research; K.K., L.Z., and M.M. performed research; K.K., L.Z., and M.M. analyzed data; and K.K., L.Z., and M.M. wrote the paper. All authors read and approved the final manuscript.

\section{Acknowledgment}

We would like to acknowledge Dr. David Sullivan, John Hopkins School of Medicine, for providing us with JHCCL and for his advices. We would also like to acknowledge Fungal Genetics Stock Center for providing us with Candida albicans knockout libraries. We acknowledge Ralph M. Parson's Foundation awarded to KGI (PI Dr. Steven Casper).

Received: 3 March 2015 Accepted: 27 May 2015

Published online: 09 June 2015

\section{References}

1. Gow NA, van de Veerdonk FL, Brown AJ, Netea MG. Candida albicans morphogenesis and host defence: discriminating invasion from colonization. Nat Rev Microbiol. 2012;10(2):112-22. doi:10.1038/nrmicro2711.

2. Wilson LS, Reyes CM, Stolpman M, Speckman J, Allen K, Beney J. The direct cost and incidence of systemic fungal infections. Value Health. 2002;5(1):2634. doi:10.1046/j.1524-4733.2002.51108.x.

3. Perlroth J, Choi B, Spellberg B. Nosocomial fungal infections: epidemiology, diagnosis, and treatment. Med Mycol. 2007;45(4):321-46. doi:10.1080/ 13693780701218689
4. DiNubile MJ, Hille D, Sable CA, Kartsonis NA. Invasive candidiasis in cancer patients: observations from a randomized clinical trial. J Infect. 2005;50(5):443-9. doi:10.1016/j.jinf.2005.01.016.

5. Fujitani S, Ricardo-Dukelow M, Kamiya T, Sullivan L, Low L. Ethnicity and other possible risk factors for candidemia at 3 tertiary care university hospitals in Hawaii. Infect Control Hosp Epidemiol. 2006;27(11):1261-3. doi:10.1086/508831.

6. Fisher JF, Sobel JD, Kauffman CA, Newman CA. Candida urinary tract infections-treatment. Clin Infect Dis. 2011;6:S457-66. doi:10.1093/cid/cir112.

7. Berman J, Sudbery PE. Candida Albicans: a molecular revolution built on lessons from budding yeast. Nat Rev Gen. 2002;3(12):918-30. doi:10.1038/nrg948.

8. Paderu P, Garcia-Effron G, Balashov S, Delmas G, Park S, Perlin DS. Serum differentially alters the antifungal properties of echinocandin drugs. Antimicrob Agents Chemother. 2007;51(6):2253-6. doi:10.1128/AAC.01536-06.

9. Vandeputte P, Ferrari S, Coste AT. Antifungal resistance and new strategies to control fungal infections. Int J Microbiol. 2012;2012:713687. doi:10.1155/2012/713687.

10. Odds FC, Brown AJ, Gow NA. Antifungal agents: mechanisms of action. Trends Microbio. 2003;11(6):272-9.

11. Behrman REWJ. FDA regulations for drug development. Science. 2010;329:33.

12. Siles SA, Srinivasan A, Pierce CG, Lopez-Ribot JL, Ramasubramanian AK. High-Throughput Screening of a Collection of Known Pharmacologically Active Small Compounds for Identification of Candida albicans Biofilm Inhibitors. Antimicrob Agents Chemother. 2013;57((8):3681-7. doi:10.1128/ AAC.00680-13.

13. Chong CR, Chen X, Shi L, Liu JO, Sullivan Jr DJ. A clinical drug library screen identifies astemizole as an antimalarial agent. Nat Chem Biol. 2006;2(8):415-6. doi:10.1038/nchembio806.

14. Gillum AM, Tsay EY, Kirsch DR. Isolation of the Candida albicans gene for orotidine-5'-phosphate decarboxylase by complementation of S. cerevisiae ura3 and E. coli pyrF mutations. MGG. 1984;198(1):179-82.

15. Noble SM, French S, Kohn LA, Chen V, Johnson AD. Systematic screens of a Candida albicans homozygous deletion library decouple morphogenetic switching and pathogenicity. Nat Gene. 2010;42(7):590-8. doi:10.1038/ng.605.

16. Rauceo JM, Blankenship JR, Fanning S, Hamaker JJ, Deneault JS, Smith FJ. Regulation of the Candida albicans cell wall damage response by transcription factor Sko1 and PAS kinase Psk1. Mol Biol Cel. 2008;19(7):2741-51. doi:10.1091/mbc.E08-02-0191.

17. Homann OR, Dea J, Noble SM, Johnson AD. A phenotypic profile of the Candida albicans regulatory network. PLoS Genet. 2009;5(12), e1000783. doi:10.1371/journal.pgen.1000783.

18. nstitute CaLS, M44-A2. Method for antifungal disk diffusion susceptibility testing of yeasts; approved guideline. 2nd ed. Wayne, PA: Clinical and Laboratory Standards Institute; 2009.

19. Arendrup MC, Park S, Brown S, Pfaller M, Perlin DS. Evaluation of CLSI M44-A2 disk diffusion and associated breakpoint testing of caspofungin and micafungin using a well-characterized panel of wild-type and fks hot spot mutant Candida isolates. Antimicrob Agents Chemother. 2011;55(5):1891-5. doi:10.1128/ AAC.01373-10.

20. ImageJ. http://imagej.nih.gov/ij/. Accessed 28 April 2015.

21. Lu Q, Wei W, Kowalski PE, Chang AC, Cohen SN. EST-based genome-wide gene inactivation identifies ARAP3 as a host protein affecting cellular susceptibility to anthrax toxin. Proc Natl Acad Sci U S A. 2004;101(49):17246-51. doi:10.1073/pnas.0407794101.

22. Hendry AT, Bakerspigel A. Factors affecting serum inhibited growth of Candida albicans and Cryptococcus neoformans. Sabouraudia. 1969;7(3):219-29.

23. Elin RJ, Wolff SM. Effect of $\mathrm{pH}$ and iron concentration on growth of Candida albicans in human serum. J Infect Dis. 1973;127(6):705-8.

24. King RD, Khan HA, Foye JC, Greenberg JH, Jones HE. Transferrin, iron, and dermatophytes. I. Serum dematophyte inhibitory component definitively identified as unsaturated transferrin. J Lab Clin Med. 1975;86(2):204-12.

25. Andes D, Nett J, Oschel P, Albrecht R, Marchillo K, Pitula A. Development and characterization of an in vivo central venous catheter Candida albicans biofilm model. Infect Immun. 2004;72(10):6023-31. doi:10.1128/ |Al.72.10.6023-6031.2004.

26. Kot EJ, Olson VL, Rolewic LJ, McClary DO. An alternate respiratory pathway in Candida albicans. Antonie Van Leeuwenhoek. 1976;42(1-2):33-48. 
27. Gale GR, Smith AB, Atkins LM, Walker Jr EM, Gadsden RH. Pharmacology of captan: biochemical effects with special reference to macromolecular synthesis. Toxicol Appl Pharmacol. 1971;18(2):426-41.

28. Lovgren T, Salmela I. In vitro sensitivity of Trichomonas vaginalis and Candida albicans to chemotherapeutic agents. Acta Pathol Microbiol Scand B. 1978;86B(3):155-8.

29. Wachtler B, Wilson D, Hube B. Candida albicans adhesion to and invasion and damage of vaginal epithelial cells: stage-specific inhibition by clotrimazole and bifonazole. Antimicrob Agents Chemother. 2011;55(9):4436-9. doi:10.1128/ AAC.00144-11.

30. Shukla S, Sauna ZE, Prasad R, Ambudkar SV. Disulfiram is a potent modulator of multidrug transporter Cdr1p of Candida albicans. Biochem Biophys Res Commun. 2004;322((2):520-5. doi:10.1016/j.bbrc.2004.07.151.

31. Molepo J, Musenge E. Clade-related phenotypic switching among fluconazole resistant Candida albicans isolates. SADJ. 2012;67(7):326-8.

32. Nash JD, Burgess DS, Talbert RL. Effect of fluvastatin and pravastatin, HMG-CoA reductase inhibitors, on fluconazole activity against Candida albicans. J Med Microbiol. 2002;51(2):105-9.

33. Ichikawa T, Yano Y, Fujita Y, Kashiwabara T, Nagao K. The enhancement effect of three sugar alcohols on the fungicidal effect of benzethonium chloride toward Candida albicans. J Dent. 2008;36(11):965-8. doi:10.1016/ j.jdent.2008.07.013.

34. Vandenbosch D, Bink A, Govaert G, Cammue BP, Nelis HJ, Thevissen K. Phytosphingosine-1-phosphate is a signaling molecule involved in miconazole resistance in sessile Candida albicans cells. Antimicrob Agents Chemother. 2012;56(5):2290-4. doi:10.1128/AAC.05106-11.

35. Kohler GA, Gong X, Bentink S, Theiss S, Pagani GM, Agabian N, et al. The functional basis of mycophenolic acid resistance in Candida albicans IMP dehydrogenase. J Biol Chem. 2005;280((12):11295-302. doi:10.1074/ jbc.M409847200.

36. Grossman LI. Evaluation of antifungal agents for endodontic use. J Dent Res. 1967:46(1):215-7

37. Hernandez Molina JM, Llosa J, Ventosa A. In vitro activity of nitroxoline against clinical isolates of Candida species. Mycoses. 1991;34(7-8):323-5.

38. Omura Y, O'Young B, Jones M, Pallos A, Duvvi H, Shimotsuura Y. Caprylic acid in the effective treatment of intractable medical problems of frequent urination, incontinence, chronic upper respiratory infection, root canalled tooth infection, ALS, etc., caused by asbestos \& mixed infections of Candida albicans, Helicobacter pylori \& cytomegalovirus with or without other microorganisms \& mercury. Acupunct Electrother Res. 2011;36(1-2):19-64.

39. De Prijck K, De Smet N, Honraet K, Christiaen S, Coenye T, Schacht E, et al. Inhibition of Candida albicans biofilm formation by antimycotics released from modified polydimethyl siloxane. Mycopathologia. 2010;169(3):167-74. doi:10.1007/s11046-009-9242-4.

40. Druglead-Octodrine. http://www.putubio.com/octodrine-cas-no-543-82-8/. Accessed 28 April 2015.

41. PubChem-Octodrine. http://pubchem.ncbi.nlm.nih.gov/compound/10982. Accessed 28 April 2015.

42. Norice CT, Smith Jr FJ, Solis N, Filler SG, Mitchell AP. Requirement for Candida albicans Sun41 in biofilm formation and virulence. Eukaryot Cell. 2007;6(11):2046-55. doi:10.1128/EC.00314-07.

43. Nobile CJ, Mitchell AP. Regulation of cell-surface genes and biofilm formation by the C. albicans transcription factor Bcr1p. Curr Biol. 2005;15(12):1150-5. doi:10.1016/j.cub.2005.05.047.

44. Hanahan D. Studies on transformation of Escherichia coli with plasmids. J Mol Biol. 1983;166(4):557-80.

45. Rasko DA, Ravel J, Okstad OA, Helgason E, Cer RZ, Jiang L, et al. The genome sequence of Bacillus cereus ATCC 10987 reveals metabolic adaptations and a large plasmid related to Bacillus anthracis pXO1. Nucleic Acids Res. 2004;32(3):977-88. doi:10.1093/nar/gkh258.

46. Jeong SY, Martchenko M, Cohen SN. Calpain-dependent cytoskeletal rearrangement exploited for anthrax toxin endocytosis. Proc Natl Acad Sci U S A. 2013;110(42):E4007-15. doi:10.1073/pnas.1316852110.

47. PubChem-BioAssay. http://pubchem.ncbi.nlm.nih.gov/assay/ assay.cgi?aid=743079. Accessed 28 April 2015.

48. Fellows EJ. The pharmacology of 2-amino-6-methylheptane. J Pharmacol Exp Ther. 1947;90(4):351-8.

\section{Submit your next manuscript to BioMed Central and take full advantage of:}

- Convenient online submission

- Thorough peer review

- No space constraints or color figure charges

- Immediate publication on acceptance

- Inclusion in PubMed, CAS, Scopus and Google Scholar

- Research which is freely available for redistribution

Submit your manuscript at www.biomedcentral.com/submit 